Pacific Journal of Mathematics

ON THE DIFFERENCE AND SUM OF A BASIC SET OF 


\title{
ON THE DIFFERENCE AND SUM OF A BASIC SET OF POLYNOMIALS
}

\author{
W. F. Newns
}

1. Introduction. For any basic set $\left(p_{n}\right)$ of polynomials, the differenced set $\left(u_{n}\right)$ and the sum $\left(v_{n}\right)$ have been defined and studied by Mikhail \& Nassif [1,2], who obtained the best possible bound for the orders of $\left(u_{n}\right)$ and $\left(v_{n}\right)$ when $\left(p_{n}\right)$ has a given order $\omega$. Their method was to estimate directly the expressions for the orders of $\left(u_{n}\right)$ and $\left(v_{n}\right)$.

The object of the present note is to indicate how these results can be obtained by an alternative line of reasoning which the author believes may throw more light on them. He observes also that either approach can be used to go a little further and determine not only the order but the type of the sets. In fact:

THEOREM 1. If $\left(p_{n}\right)$ is of increase $(\omega, \gamma)$, then $\left(u_{n}\right)$ has increase at most $\max \{(\omega, \gamma),(1,1 / 2 \pi)\}$.

Theorem 2. Let $\left(p_{n}\right)$ have increase $(\omega, \gamma)$. Then

(i) If lim sup $D_{n} / n=\alpha<\infty,\left(v_{n}\right)$ has increase at most $(\omega+\alpha, \infty)$,

(ii) If $D_{n}^{D_{n} / n}=0\left(n^{\alpha}\right)$ and $\gamma<\infty$ (so that $\omega>0$ ), the increase of $\left(v_{n}\right)$ is at most $(\omega+\alpha, 0)$.

Case (ii) applies in particular (with $\alpha=1$ ) to simple sets.

2. Spaces of integral functions. Let $f$ be an integral function, $\rho$ its order. If $0<\rho<\infty$, the rate of increase of $f$ is $(\rho, \sigma)$ where $\sigma$ is the type of $f$. If $\rho=0$ we put $\sigma=\infty$, and if $\rho=\infty$ we put $\sigma=0$ and again define the rate of increase of $f$ as $(\rho, \sigma)$. We use lexicographic order, so that $\left(\rho_{1}, \sigma_{1}\right) \leqq\left(\rho_{2}, \sigma_{2}\right)$ means that either $\rho_{1}<\rho_{2}$ or $\rho_{1}=\rho_{2}$ and $\sigma_{1} \leqq \sigma_{2}$.

The set $I(\rho, \sigma)$ of all integral functions of increase not exceeding $(\rho, \sigma)$ is a vector space under the usual operations. The space $I(\infty, 0)$ of all integral functions is an $\mathscr{F}$-space under the topology of uniform convergence on compact sets (the compact-open topology). If $\rho<\infty$, $I(\rho, \sigma)$ is an $\mathscr{F}$-space under a (unique) topology $\mathscr{T}(\rho, \sigma)$ finer than that induced on it by the topology $\mathscr{T}(\infty, 0)$ of $I(\infty, 0)$, (c.f. [3] $\S 5$, p. 438). These may be defined as follows. Put

$$
\begin{aligned}
& |f|_{\infty, r}=\sum\left|a_{k}\right| r^{k} \\
& |f|_{\rho, r}=\sum(k / e \rho)^{k / \rho}\left|a_{k}\right| r^{k}
\end{aligned}
$$

Received July 1, 1963. 
for $f(z)=\sum a_{n} z^{n}$. Then $\mathscr{T}(\rho, 0)$ is defined by the semi-norms $|f|_{\rho, r}$ for all finite $r, \mathscr{T}(\rho, \infty)$ by $|f|_{\rho_{1}, r}$ for $\rho_{1}>\rho$ and all finite $r$, and $\mathscr{T}(\rho, \sigma)$ for $0<\sigma<\infty$ by $|f|_{\rho, r}$ for $r<\sigma^{-1 / \rho}$.

We denote by $I_{0}(\rho, \sigma)$ the set of those functions of $I(\rho, \sigma)$ which vanish at the origin: $I_{0}(\rho, \sigma)=\{g \in I(\rho, \sigma): g(0)=0\} . \quad I_{0}(\rho, \sigma)$, being a closed subspace of $I(\rho, \sigma)$, is an $\mathscr{F}$-space under the induced structure.

3. Rate of increase of a basic set. As with functions, we define the rate of increase of a basic set to be the pair $(\omega, \gamma)$ where $\omega$ is the order, $\gamma$ the type if $0<\omega<\infty$ and similar conventions where $\omega=0$ or $\infty$. We again use lexicographic order and recall the following result [6]:

THEOREM 3. A basic set $\left(p_{n}\right)$ is of increase not exceeding $(\omega, \gamma)$ if and only if it is effective for $I(\rho, \sigma)$ in $\mathscr{T}(\infty, 0)$ for all $(\rho, \sigma)<(1 / \omega, 1 / \gamma)$.

4. The difference operator. For any integral function $g$ we put $\Delta g=f$, where

$$
f(z)=g(z+1)-g(z) .
$$

THEOREM 4. The difference operator $\Delta$ is a continuous linear mapping of $I(\rho, \sigma)$ onto itself.

A proof that $\Delta$ is a linear mapping of $I(\rho, \sigma)$ onto itself will be found in [5] (pp. 21-24) and [4] (Theorem I). Continuity of $\Delta$ for the compact-open topology (induced by $\mathscr{T}(\infty, 0)$ ) is easily checked. Continuity for $\mathscr{T}(\rho, \sigma)$ now follows from the closed graph theorem.

Clearly $\Delta$ is not a bijection: its kernel contains not only constants but any function of period 1. Since the only functions of period 1 and increase less than $(1,2 \pi)$ are constants, we have:

THEOREM 5. If $(\rho, \sigma)<(1,2 \pi)$, then $\Delta$ is an isomorphism between the $\mathscr{F}$-spaces $I_{0}(\rho, \sigma)$ and $I(\rho, \sigma)$.

Under the hypotheses of Theorem 5, $\Delta: I_{0}(\rho, \sigma) \rightarrow I(\rho, \sigma)$ has a continuous inverse $\mathscr{S}: I(\rho, \sigma) \rightarrow I_{0}(\rho, \sigma)$. If $f=\Delta g$ we have $g=\mathscr{S} f$ and call $g$ the sum of $f$.

5. The differenced set. In defining the differenced set $\left(u_{n}\right)$ of a given basic set $\left(p_{n}\right)$, there is no loss of generality in taking $p_{0}(z)=1$.

${ }^{1}$ For this reference, which he had failed to trace, the author is indebted to Dr. J. M. Whittaker. 
Then

$$
u_{n}=\Delta p_{n+1}
$$

and the set $\left(u_{n}\right)$ is basic with respect to the representation

$$
z^{n}=\sum_{0}^{\infty} \Pi_{k+1}\left(\phi_{n+1}\right) u_{k}(z),
$$

where

$$
\phi_{n+1}(z)=\mathscr{S} z^{n}
$$

To prove Theorem 1 , let the increase of $\left(p_{n}\right)$ be $(\omega, \gamma)$. If $\omega$ is infinite there is nothing to prove, so we suppose $\omega<\infty$. Let $(\rho, \sigma)<\min \{(1 / \omega, 1 / \gamma),(1,2 \pi)\}, \sigma<\infty$ and let $f \in I(\rho, \sigma)$. Then $g=$ $\mathscr{S} f \in I(\rho, \sigma)$ and (Theorem 3$)$

$$
g=\sum_{0}^{\infty} \Pi_{k}(g) p_{k} \quad(\mathscr{T}(\infty, 0)) .
$$

Since $\Delta$ is continuous in $\mathscr{T}(\infty, 0)$,

$$
f=\Delta g=\sum_{0}^{\infty} \Pi_{k}(g) \Delta p_{k}=\sum_{1}^{\infty} \Pi_{k}(g) u_{k-1}=\sum_{0}^{\infty} \Pi_{k+1}(g) u_{k},
$$

showing that $f$ is represented in $\mathscr{T}(\infty, 0)$ by a series of the required form. To prove that this is the basic series of $f$, it is obvious that $f \rightarrow \Pi_{k+1}(g)$ is continuous (being composed of the continuous functions $\mathscr{S}$ and $\Pi_{k+1}$ ) and hence the series is basic under the inverse matrix

$$
\Pi_{k+1}\left(\mathscr{S} z^{n}\right)=\Pi_{k+1}\left(\phi_{n+1}\right) .
$$

Theorem 1 now follows from Theorem 3.

REMARK. Nothing in this argument depends on the $p_{n}(z)$ being polynomials. They may be integral functions of any order.

6. The sum of a basic set. Given a basic set $\left(p_{n}\right)$ of polynomials, ${ }^{2}$ the $\operatorname{sum}\left(v_{n}\right)$ is defined by

$$
v_{n}=\mathscr{S} p_{n-1} \quad(n>0), \quad v_{0}=1 .
$$

This set is basic with respect to the representation

$$
z^{n}=\sum_{1}^{\infty} \Pi_{k-1}\left(\vartheta_{n-1}\right) v_{l k} \quad(n>0),
$$

where $\vartheta_{n-1}(z)=\Delta z^{n}$.

${ }^{2}$ In the definition of $\left(v_{n}\right)$ we could allow the $\left(p_{n}\right)$ to be integral functions of increase $<(1,2 \pi)$. However, Theorem 2 applies only to sets of polynomials. 
Proceeding heuristically, let $f$ be given (with $f(0)=0$ ) and put $g=\Delta f$. Then

$$
g=\sum_{0}^{\infty} \Pi_{k}(g) p_{k}
$$

and we obtain

$$
f=\mathscr{S} g=\sum_{0}^{\infty} \Pi_{k}(g) \mathscr{S} p_{k}=\sum_{0}^{\infty} \Pi_{k}(g) v_{k+1}
$$

a series with continuous coefficients (composed of $\Delta$ and $\Pi_{k-1}$ ) which is therefore basic under

$$
\Pi_{k-1}\left(\Delta z^{n}\right)=\Pi_{k-1}\left(\vartheta_{n-1}\right) .
$$

This argument is valid for all $f \in I_{0}\left(\rho_{0}, \sigma_{0}\right)$ only if $\left(\rho_{0}, \sigma_{0}\right)$ satisfies certain requirements. For equation (1) to hold in (say) $\mathscr{T}(\infty, 0)$ we need $\left(\rho_{0}, \sigma_{0}\right)<(1 / \omega, 1 / \gamma)$. For $\mathscr{S}$ to be well-defined, we need $\left(\rho_{0}, \sigma_{0}\right)<(1,2 \pi)$. But to apply $\mathscr{S}$ to (1) to obtain (2), we need (1) to hold in a topology $\mathscr{T}\left(\rho_{1}, \sigma_{1}\right)$ in which $\mathscr{S}$ is continuous, i.e. one for which $\left(\rho_{1}, \sigma_{1}\right)<(1,2 \pi)$. The problem arises as to which $\left(\rho_{0}, \sigma_{0}\right)$ will satisfy these requirements and the answer is given by:

THEOREM 6. Suppose that $\left(p_{n}\right)$ is effective for $I(\rho, \sigma)$ in $\mathscr{T}(\infty, 0)$, $(0<\rho<\infty, 0<\sigma<\infty)$, and that $D_{n}^{D_{n} / n}=0\left(n^{\beta}\right)$. Given $\rho_{1}\left(0<\rho_{1}<\infty\right)$ put $\left(1 / \rho_{0}\right)=(1 / \rho)+\left(\beta / \rho_{1}\right)$. Then $\left(p_{n}\right)$ is effective for $I\left(\rho_{0}, \sigma_{0}\right)$ in $\mathscr{T}\left(\rho_{1}, 0\right)$ for all finite $\sigma_{0}$.

We first complete the proof of Theorem 2. For case (i), let $\rho_{0}<(1 / \omega+\alpha)$ and choose $\beta>\alpha$ such that $\rho_{0}<(1 / \omega+\beta)$. Put $\left(1 / \rho_{0}\right)=$ $(1 / \rho)+\beta$ so that $\rho<(1 / \omega)$. The hypotheses of Theorem 6 hold with $\rho_{1}=1$ and so the heuristic argument above holds for $\left(\rho_{0}, \sigma_{0}\right)$ for any finite $\sigma_{0}$. This being true for any $\rho_{0}<(1 / \omega+\alpha)$, case (i) follows from Theorem 3.

For case (ii), we put $\rho=(1 / \omega), \beta=\alpha$ and choose $\sigma<(1 / \gamma)$. We conclude similarly that $\left(v_{n}\right)$ is effective for $I\left(\rho_{0}, \sigma_{0}\right)$ in $\mathscr{T}(\infty, 0)$ when $\left(1 / \rho_{0}\right)=\omega+\alpha$ and $\sigma_{0}$ is finite. By Theorem 3 , this is equivalent to the stated result.

We now prove Theorem 6. Put

$$
\gamma= \begin{cases}\sup \left\{\beta-D_{n} / n\right\} & \left(e \rho_{1} \geqq 1\right) \\ \inf \left\{\beta-D_{n} / n\right\} & \left(e \rho_{1}<1\right) .\end{cases}
$$

Since $D_{n} \geqq n$ and $\lim \sup D_{n} / n \leqq \beta, \gamma$ is finite. Also we are dealing with a Cannon set so that effectiveness is equivalent to absolute effectiveness. Let $0<\sigma_{0}<\infty$. We have to prove $([3], \S \S 7,8)$ : given 
$r_{1}<\infty$, there exist $M$ and $r_{0}<\sigma_{0}^{-1 / \rho_{0}}$ such that

$$
\sum_{l}\left|\pi_{n l}\right| \sum_{k}\left(\frac{k}{e \rho_{1}}\right)^{k / \rho_{1}}\left|p_{l k}\right| r_{1}^{k} \leqq M\left(\frac{n}{e \rho_{0}}\right)^{n / \rho_{0}} r_{0}^{n} .
$$

Put $s=\rho_{0}^{1 / \rho_{0}} \rho^{-1 / \rho} \rho_{1}^{-\beta / \rho_{1}} c^{1 / \rho_{1}}\left(e \rho_{1}\right)^{/ \rho_{1}} \sigma^{-1 / \rho} \sigma_{0}^{1 / \rho_{0}}$ where $c$ is chosen large enough for $s \geqq 1$ and $D_{n}^{D_{n} / n} \leqq c n^{\beta}$. The left-hand member of the inequality to be proved may be written

$$
\sum_{l}\left|\pi_{n l}\right| \sum_{k}\left(\frac{k}{e \rho_{1}}\right)^{k / \rho_{1}} s^{-k}\left|p_{l k}\right|\left(r_{1} s\right)^{k}
$$

The largest value of $k$ appearing in this is $D_{n}$. Since the sequence $\left(k / e \rho_{1}\right)^{k / \rho_{1}} s^{-k}$ increases to $\infty$ from some point on, we have $\left(k / e \rho_{1}\right)^{k / \rho_{1}} s^{-k} \leqq$ $A\left(D_{n} / e \rho_{1}\right)^{D_{n} / \rho_{1}} s^{-D_{n}}$ for some $A$ and all $n$. Also

$$
\sum_{l}\left|\pi_{n l}\right| \sum_{k}\left|p_{l k}\right|\left(r_{1} s\right)^{k} \leqq B \sum_{l}\left|\pi_{n l}\right| M_{l}(R)=B \omega_{n}(R)
$$

for $R>r_{1} s$, and since $\left(p_{n}\right)$ is effective for $I(\rho, \sigma)$ in $\mathscr{T}(\infty, 0)$, there exist $C$ and $r<\sigma^{-1 / P}$ such that

$$
\omega_{n}(R) \leqq C\left(\frac{n}{e \rho}\right)^{n / \rho} r^{n} .
$$

Finally, since $D_{n} \geqq n$ and $s \geqq 1$ we have $s^{-D_{n}} \leqq s^{-n}$. Thus the lefthand member of the inequality to be proved does not exceed

$$
\begin{aligned}
& A\left(\frac{D_{n}}{e \rho_{1}}\right)^{D_{n} / \rho_{1}} s^{-n} B C\left(\frac{n}{e \rho}\right)^{n / \rho} r^{n} \\
& \quad \leqq A B C c^{n / \rho_{1}}\left(\frac{n}{e \rho_{1}}\right)^{\beta n / \rho_{1}}\left(e \rho_{1}\right)^{\left(\beta n-D_{n}\right) / \rho_{1}} s^{-n}\left(\frac{n}{e \rho}\right)^{n / \rho} r^{n} \leqq M\left(\frac{n}{e \rho_{0}}\right)^{n / \rho_{0}} r_{0}^{n},
\end{aligned}
$$

where $r_{0}=\rho_{0}^{1 / \rho_{0}} c^{1 / \rho_{1}} \rho_{1}^{-\beta / \rho_{1}}\left(e \rho_{1}\right)^{/ \rho_{1}} \mathcal{S}^{-1} \rho^{-1 / \rho} r<\sigma_{0}^{-1 / \rho_{0}}$, as required.

7. Examples. Let $\left(\nu_{n}\right)$ be a sequence of even nonnegative integers, $\left(\gamma_{n}\right)$ a sequence of real numbers and $\omega$ a nonnegative real number. Consider the set

$$
\begin{aligned}
p_{2 n}(z) & =z^{2 n} \\
p_{2 n+1}(z) & =z^{2 n+1}+((2 n+1) !)^{\omega} \gamma_{n}^{2 n+1} z^{\nu_{n}} .
\end{aligned}
$$

Example (i). $\nu_{n}=2 n, \gamma_{n}=\log (2 n+1)$. It will be found that $\left(p_{n}\right)$ has increase $(\omega, \infty)$ and $\left(v_{n}\right)$ has increase $(\omega+1, \infty)$.

EXAMPle (ii). $\quad \nu_{n}=2 n, \gamma_{n}=(1 / \log (2 n+1))(n>0), \omega>0$. Here $\left(p_{n}\right)$ is of increase $(\omega, 0)$ and $\left(v_{n}\right)$ of increase $(\omega+1,0)$.

EXAMPLE (iii). Choose $\nu_{n}$ so that $\nu_{n} / 2 n \rightarrow \alpha \geqq 1$, but $\left(\left(\nu_{n} !\right)^{1 / 2 n} /(2 n)^{\alpha}\right) \rightarrow$ 
$\infty$. Put $\gamma_{n}=\sqrt{ }\left((2 n)^{\alpha} /\left(\nu_{n} !\right)^{1 / 2 n}\right), \omega>0$. Here lim $\sup D_{n} / n=\alpha$ and $\left(p_{n}\right)$ is of increase $(\omega, 0)$, but $\left(v_{n}\right)$ is of increase $(\omega+\alpha, \infty)$.

\section{REFERENCES}

1. N. N. Mikhail and M. Nassif, Assiut Univ. Bull. Sci. Tech.

2. L Pacific J. Math., 11 (1961), 1099-1107.

3. W. F. Newns, Phil. Trans. Roy. Soc. London, A 245, (1953), 429-468.

4. Sheila Scott, Proc. Camb. Phil. Soc. XXXI (1935) 543-554.

5. J. M. Whittaker, Interpolatory function theory, Cambridge University Press, (1935).

6. - Sur les Séries de Base de Polynomes Quelconques, Paris: Gauthier-Villars, (1949).

THE UNIVERSITY, LIVERPOOL 


\title{
PACIFIC JOURNAL OF MATHEMATICS
}

\author{
EDITORS
}

\author{
Robert Osserman \\ Stanford University \\ Stanford, California \\ M. G. Arsove \\ University of Washington \\ Seattle 5, Washington
}

\author{
J. Dugundji \\ University of Southern California \\ Los Angeles 7, California \\ Lowell J. Paige \\ University of California \\ Los Angeles 24, California
}

\section{ASSOCIATE EDITORS}
E. F. BECKENBACH
B. H. NEUMANN
F. WOLF
K. YOSHIDA

\section{SUPPORTING INSTITUTIONS}

\author{
UNIVERSITY OF BRITISH COLUMBIA \\ CALIFORNIA INSTITUTE OF TECHNOLOGY \\ UNIVERSITY OF CALIFORNIA \\ MONTANA STATE UNIVERSITY \\ UNIVERSITY OF NEVADA \\ NEW MEXICO STATE UNIVERSITY \\ OREGON STATE UNIVERSITY \\ UNIVERSITY OF OREGON \\ OSAKA UNIVERSITY \\ UNIVERSITY OF SOUTHERN CALIFORNIA
}

\author{
STANFORD UNIVERSITY \\ UNIVERSITY OF TOKYO \\ UNIVERSITY OF UTAH \\ WASHINGTON STATE UNIVERSITY \\ UNIVERSITY OF WASHINGTON \\ AMERICAN MATHEMATICAL SOCIETY \\ CALIFORNIA RESEARCH CORPORATION \\ SPACE TECHNOLOGY LABORATORIES \\ NAVAL ORDNANCE TEST STATION
}

Mathematical papers intended for publication in the Pacific Journal of Mathematics should by typewritten (double spaced), and on submission, must be accompanied by a separate author's résumé. Manuscripts may be sent to any one of the four editors. All other communications to the editors should be addressed to the managing editor, L. J. Paige at the University of California, Los Angeles 24, California.

50 reprints per author of each article are furnished free of charge; additional copies may be obtained at cost in multiples of 50 .

The Pacific Journal of Mathematics is published quarterly, in March, June, September, and December. Effective with Volume 13 the price per volume (4 numbers) is $\$ 18.00$; single issues, $\$ 5.00$. Special price for current issues to individual faculty members of supporting institutions and to individual members of the American Mathematical Society: $\$ 8.00$ per volume; single issues $\$ 2.50$. Back numbers are available.

Subscriptions, orders for back numbers, and changes of address should be sent to Pacific Journal of Mathematics, 103 Highland Boulevard, Berkeley 8, California.

Printed at Kokusai Bunken Insatsusha (International Academic Printing Co., Ltd.), No. 6, 2-chome, Fujimi-cho, Chiyoda-ku, Tokyo, Japan.

PUBLISHED BY PACIFIC JOURNAL OF MATHEMATICS, A NON-PROFIT CORPORATION

The Supporting Institutions listed above contribute to the cost of publication of this Journal, but they are not owners or publishers and have no responsibility for its content or policies. 


\section{Pacific Journal of Mathematics}

\section{Vol. 14, No. $2 \quad$ June, 1964}

Tom M. (Mike) Apostol and Herbert S. Zuckerman, On the functional equation $F(m n) F((m, n))=F(m) F(n) f((m, n)) \ldots \ldots \ldots \ldots \ldots \ldots \ldots \ldots \ldots \ldots \ldots$

Reinhold Baer, Irreducible groups of automorphisms of abelian groups . . . . . . . 385

Herbert Stanley Bear, Jr., An abstract potential theory with continuous kernel . . . . 407

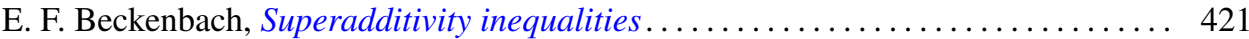

R. H. Bing, The simple connectivity of the sum of two disks . . . . . . . . . . . 439

Herbert Busemann, Length-preserving maps ...................... 457

Heron S. Collins, Characterizations of convolution semigroups of measures . . . . . . 479

Paul F. Conrad, The relationship between the radical of a lattice-ordered group and complete distributivity............................ 493

P. H. Doyle, III, A sufficient condition that an arc in $S^{n}$ be cellular . . . . . . . . . 501

Carl Clifton Faith and Yuzo Utumi, Intrinsic extensions of rings . . . . . . . . . . 505

Watson Bryan Fulks, An approximate Gauss mean value theorem . . . . . . . . . . 513

Arshag Berge Hajian, Strongly recurrent transformations . . . . . . . . . . . . . 517

Morisuke Hasumi and T. P. Srinivasan, Doubly invariant subspaces. II . . . . . . . 525

Lowell A. Hinrichs, Ivan Niven and Charles L. Vanden Eynden, Fields defined by

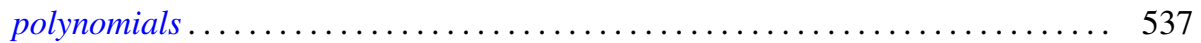

Walter Ball Laffer, I and Henry B. Mann, Decomposition of sets of group

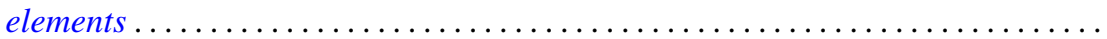

John Albert Lindberg, Jr., Algebraic extensions of commutative Banach

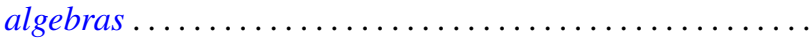

W. Ljunggren, On the Diophantine equation $C x^{2}+D=y^{n} \ldots$

M. Donald MacLaren, Atomic orthocomplemented lattices ....

Moshe Marcus, Transformations of domains in the plane and applications in the

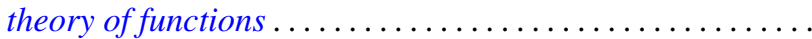

Philip Miles, $B^{*}$ algebra unit ball extremal points . .................. 627

W. F. Newns, On the difference and sum of a basic set of polynomials . . . . . . . 639

Barbara Osofsky, Rings all of whose finitely generated modules are injective ...... 645

Calvin R. Putnam, Toeplitz, matrices and invertibility of Hankel matrices . . . . . . . 651

Shoichiro Sakai, Weakly compact operators on operator algebras . . . . . . . . . 659

James E. Simpson, Nilpotency and spectral operators . . . . . . . . . . . . . 665

Walter Laws Smith, On the elementary renewal theorem for non-identically

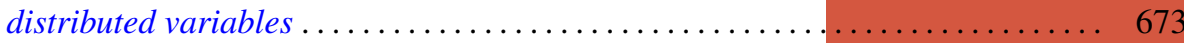

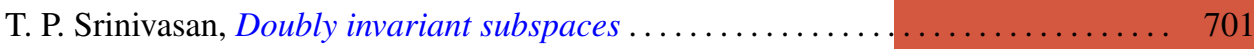

J. Roger Teller, On the extensions of lattice-ordered groups . . . . . . . . . . . . 709

Robert Charles Thompson, Unimodular group matrices with rational integers as

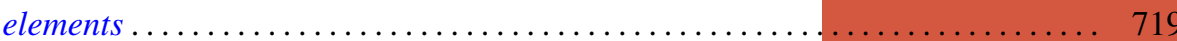

J. L. Walsh and Ambikeshwar Sharma, Least squares and interpolation in roots of unity

Charles Edward Watts, A Jordan-Hölder theorem .................... 731

Kung-Wei Yang, On some finite groups and their cohomology .............. 735

Adil Mohamed Yaqub, On the ring-logic character of certain rings ............ 741

Paul Ruel Young, A note on pseudo-creative sets and cylinders 